\title{
STRATEGI PEMASARAN DALAM MENINGKATKAN VOLUME PENJUALAN SUPLEMEN MAKANAN IMFORCE KAPLET
}

\author{
Melan Susanty Purnamasari \\ Gilang Kurniawan Gumelar \\ Program Studi Administrasi Bisnis, Universitas Tulang Bawang - Lampung \\ E-mail: meilan.susanty@gmail.com
}

\begin{abstract}
ABSTRAK
Penelitian ini bertujuan untuk menganilis strategi pemasaran Suplemen Makanan Imforce Kaplet pada PT. Mahakam Beta Farma khususnya bauran pemasaran (marketing mix) yang diterapkan perusahaan. Kemudian untuk mengetahui hasil kekuatan (strength), kelemahan (weakness), peluang (opportunities), dan ancaman (threat) serta gambaran strateginya sehingga dapat diaplikasikan untuk peningkatan penjualan produk. Dengan menggunakan teknik penelitian SWOT, Matriks, IFAS, dan EFAS serta diagram cartesius. Penelitian ini menggunakan metode kualitatif, yaitu studi khusus yang menghasilkan data-data deskriptif yang dituangkan dalam kata-kata. Teknik pengumpulan data pada penelitian ini penulis melakukan kunjungan langsung ke kantor PT. Mahakam Beta Farma cabang Lampung untuk melakukan wawancara pribadi dengan Bapak I Wayan Sudana sebagai District Manager dan dilengkapi dengan data-data penjualan beberapa tahun kebelakang. Kesimpulan dari analisis yang dilakukan pada strategi pemasaran PT. Mahakam Beta Farma adalah perusahaan telah menjalankan strategi pemasaran dengan benar dan tepat serta pada perhitungan analisis SWOT yang dituangkan pada diagaram cartesius perusahaan tersebut berada di posisi kuadran I yaitu Gowth. Yang mana perusahaan dapat mengembangkan, mempertahankan, dan meningkatkan kualitas produk agar masyarakat terus percaya pada produk Imforce kaplet yang mengandung banyak vitamin yang sangat baik untuk menjaga dan memelihara daya tahan tubuh.
\end{abstract}

Kata kunci: strategi pemasaran, bauran pemasaran, analisis SWOT, matrika IFAS, matriks EFAS, diagram Cartesius.

\section{PENDAHULUAN}

Fenomena yang berkembang pada akhirakhir ini, para orang tua bersaing untuk mencerdaskan anaknya dengan cara berusaha mendapatkan pendidikan yang berkualitas tingi serta menjaga kesehatan tubuh anaknya. Akibatnya para orang tua tersebut menjadi panik dengan berlombalomba mempertinggi kualitas anaknya dengan cara memberikan berbagai jenis makanan sehat dan berbagai produk suplemen makanan yang ditawarkan.

Kekhawatiran orang tua akan perkembangan anak akan terlihat dari seringkali orang tua mengandalkan pemberian multivitamin terutama pada anak yang sulit makan. Mereka pun menyiasatinya dengan memberikan vitamin penambah nafsu makan. Menurut Nancy Showen, M.D seorang pakar gizi dari childern's Hospital, Oakland, California, mengatakan vitamin bukan dianjurkan 
untuk menambah nafsu makan. Jika kondisi anak tidak sehat, tentu anak akan menjadi kurang nafsu makan. Sembuhkan sakitnya terlebih dahulu, setelah pulih baru bisa dibantu dengan pemberian vitamin (Zoelandri, 2007).

Pemberian multivitamin atau suplemen makanan bisa jadi bermanfaat bagi tumbuh kembang anak. Puslitbang Farmasi Depkes RI menganjurkan sebaiknya orang tua berkonsultasi terlebih dahulu dengan dokter anak sebelum memberikan suplemen. Syarat pemberian multivitamin yang tepat ialah tidak melebihi dosis dosis yang dianjurkan atau Recommended Daily Allomance (RDA), untuk melengkapi kebutuhan nutrisi anak yang tidak bisa dipenuhi hanya dengan makanan seharihari.

Secara alami vitamin sebenarnya ada yang bisa diproduksi sendiri oleh tubuh, misalnya vitamin $\mathrm{K}$, dan ada pula vitamin yang tidak bisa diproduksi oleh tubuh. Pemberian vitamin tambahan dari luar tubuh memang bisa dilakukan, dengan catatan vitamin tersebut memang dibutuhkan anak, apabila tidak dikhawatirkan akan menimbulkan efek samping.

Pada tahun 2000 Puslitbang Farmasi Depkes RI telah melakukan survey konsumsi suplemen makanan. Hasil penelitian tersebut menunjukan bahwa sebesar $78.1 \%$ wanita mengonsumsi suplemen makanan (Ramadani, 2005). Penelitian yang dilakukan Sudiyanto, dkk (2001) yang melibatkan para ibu yang memiliki balita di kota Bandar Lampung, menemukan bahwa tingginya presentase ibu yang memberikan suplemen makanan pada anak balitanya mencapai $87 \%$.

Wahlqvist (2002) menyebutkan bahwa meningkatkan peggunaan suplemen makanan disebabkan oleh perubahan pola makan dan gaya hidup, dimana saat ini masyarakat cenderung lebih menyukai jenis makanan yang praktis, siap saji, berkadar lemak tinggi yang banyak beredar di pasaran (Ramadani, 2005).

Saat ini semakin banyak masyarakat yang tergiur untuk mencoba mengonsumsi suplemen makanan dan bahkan sudah menjadi bagian dari gaya hidup di era modern. Hal ini tentunya dimanfaatkan oleh banyak perusahaan produsen suplemen makanan untuk berlomba-lomba berinovasi memproduksi suplemen makanan yang kaya akan kandungan gizi dan vitamin yang sangat berpengaruh untuk kebaikan kesehatan. Gencarnya promosi para produsen yang memanfaatkan peluang keuntungan yang besar ini melalui berbagai media.

PT. Mahakam Beta Farma adalah salah satu produsen suplemen makananan dengan standar kualitas internasional yang memiliki produk-produk bermanfaat dan bermutu bagi masyarakat. Perusahaan tersebut telah menghasilkan beberapa produk unggulannya. Salah satu produk yang dimiliki PT Mahakam Beta Farma adalah Imforce Kaplet. Dipilihnya produk suplemen makanan Imforce Kaplet sebagai objek penelitian adalah dengan pertimbangan bahwa suplemen tersebut mempunyai banyak kandungan gizi yang baik untuk menjaga dan memelihara daya tahan tubuh. Produk tersebut merupakan supelemen makanan yang mempunyai kandungan Echinacea Purpurea, Zinc Picolinate dan Black Elderberry, yang mana Echinacea Purpurea dan Black Eldeberry dapat merangsang sistem imun sehingga lebih kebal dan selalu dalam kondisi optimal untuk melawan serangan penyakit dan Zinc Picolinate yang merupakan komponen dalam tubuh yang membantu menjaga sistem daya tahan tubuh dan mempercepat penyembuhan luka. Suplemen makanan ini dapat membantu menjaga dan memelihara daya tahan tubuh, juga digunakan untuk mempercepat proses 
pemulihan dari sakit serta obat ini juga dapat dikonsumsi untuk semua kalangan usia.

\subsection{Latar Belakang}

$\begin{array}{lrr}\text { Banyaknya } & \text { faktor-faktor } & \text { yang } \\ \text { melatarbelakangi } & \text { seseorang } & \text { untuk }\end{array}$ mengonsumsi suplemen makanan, membuat banyak perusahaan industri farmasi yang berinovasi menciptakan produk suplemen makanan dan berlombalomba melakukan berbagai strategi pemasaran yang berbeda-beda melalui berbagai cara. Salah satu perusahaan yang turut meramaikan pemasaran produk suplemen makanan tersebut adalah PT. Mahakam Beta Farma dengan produk Imforce Kaplet.

Berdasarkan latar belakang dan perumusan masalah tersebut, maka masalah tersebut dapat dirumuskan yaitu "Bagaimanakah strategi pemasaran yang dilakukan oleh PT. Mahakam Beta Farma dalam meningkatkan volume penjualan produk suplemen makanan Imforce Kaplet" mengingat semakin banyaknya masyarakat yang mulai sadar akan pentingnya menjaga dan memelihara daya tahan tubuh.

\subsection{Rumusan Masalah}

Berdasarkan latar belakang dan penelitian yang telah dirumuskan, maka penelitian ini bertujuan untuk mengetahui strategi pemasaran yang dilaksanakan oleh PT. Mahakam Beta Farma dalam meningkatkan volume penjualan suplemen makanan Imforce Kaplet di Bandar Lampung.

\subsection{Tujuan Penelitian}

Berdasarkan latar belakang dan penelitian yang telah dirumuskan, maka penelitian ini bertujuan untuk mengetauhi strategi pemasaran yang dilaksanakan oleh PT. Mahakam Beta Farma dalam meningkatkan volume penjualan suplemen makanan Imforce Kaplet di Bandar Lampung.

\section{TINJAUAN PUSTAKA}

\subsection{Pengertian Strategi}

Strategi adalah rencana yang disatukan, luas dan berintegrasi yang menghubungkan keunggulan strategis perusahaan dengan tantangan lingkungan, yang dirancang untuk memastikan bahwa tujuan utama dari perusahaan dapat dicapai melalui pelaksanaan yang tepat oleh organisasi (Glueck dan Jauch, p.9, 1989). Kata strategi berasal dari bahasa Yunani "strategia" yang diartikan sebagai "the art of the general" atau seni seorang panglima yang biasanya digunakan dalam peperangan.

\subsection{Pengertian Pemasaran}

Pemasaran dapat memiliki sebagai suatu kegiatan menyeluruh, terpadu,dan terencana, yang dilakukan oleh sebuah organisasi atau institusi dalam melakukan usaha agar mampu mengakomodir permintaan pasar dengan cara menciptakan produk bernilai jual, menentukan harga, mengkomunikasikan, menyampaikan, dan saling bertukar tawaran yang bernilai bagi konsumen, klien, mitra, dan masyarakat umum. Beberapa ahli pernah menjelaskan tentang pengertian pemasaran, diantaranya adalah:

1. Menurut John Westwood, pengertian pemasaran adalah sebuah usaha terpadu yang dilakukan untuk memenuhi kebutuhan konsumen dan memberikan keuntungan/laba kepada perusahaan.

2. Menurut Tung Dasem Waringin, pengertian pemasaran adalah media untuk mengkomunikasikan sebuah nilai tambah yang lebih tinggi.

3. Menurut Kotler, pengertian pemasaran adalah aktivitas sosial dan sebuah pengaturan yang dilakukan oleh perorangan ataupun sebuah kelompok 
orang dengan tujuan untuk mendapatkan tujuan mereka dengan jalan membuat produk dan menukarkannya dengan besaran nominal tertentu ke pihak lain.

\subsection{Tujuan Pemasaran}

Tujuan Pemasaran adalah mengenal dan memahami pelanggan sedemikian rupa sehingga produk yang dijual akan cocok sesuai dengan keinginan pelanggan, sehingga produk tersebut dapat terjual dengan sendirinya. Idealnya pemasaran menyebabkan pelanggan siap membeli sehingga yang harus difikirkan selanjutnya adalah bagaimana membuat produk tersebut tersedia. Pengertian pemasaran oleh beberapa ahli diartikan menjadi :

a William J Stanton, menyatakan bahwa Pemasaran adalah keseluruhan intern yang berhubungan dengan kegiatankegiatan usaha yang bertujuan untuk merencanakan, menentukan harga, mempromosikan dan mendistribusikan barang dan jasa yang akan memuaskan kebutuhan pembeli baik pembeli yang ada maupun pembeli yang potensial.

b Philip dan Duncan. Pemasaran meliputi semua langkah yang digunakan atau diperlukan untuk menempatkan barangbarang berwujud kepada konsumen. American Marketing Association Pemasaran meliputi pelaksanaan

c kegiatan usaha niaga yang diarahkan pada arus aliran barang dan jasa dari produsen kepada konsumen.

\section{METODE PENELITIAN}

\subsection{Jenis Penelitian}

Dalam penelitian ini penulis melakukan penelitian dengan metode kualitatif. Penelitian yang menggunakan metode kualitatif bertujuan mengenali atau membangun satu proposi atau menjelaskan makna dibalik realita atau peristiwa yang berlangsung di lapangan.

Dalam metode penelitian kualitatif akan menggunakan prosedur penelitian yang menghasilkan data berupa deskriptif dari ucapan atau tulisan dan prilaku objek itu sendiri. Penelitian kualitatif lebih menekankan pada data yang berupa kata atau gambar dan tidak menekan pada angka, selain itu penelitian ini lebih menekankan pada proses dari produk atau outcome.

\subsection{Lokasi dan Waktu Penelitian}

Penelitian dilakukan dikantor PT. Mahakam Beta Farma yang beralamat di Jalan Tembesu 2 No.15A, Campang Raya, Tanjung karang Timur, Bandar Lampung. Lokasi penelitian ini dilakukan secara sengaja (purposive) dengan mempertimbangkan kelengkapan dan kemudahan data yang didapat serta kegiatan penelitian ini dilakukan pada bulan Januari 2019.

\subsection{Teknik Analisis Data}

Adapun teknik pengolahan data pada penelitian ini dengan menggunakan metode deskriptif kualitatif. Yaitu data yang dikumpulkan berupa gambar, kata-kata dan bukan angka. Analisa dalam penelitian kualitatif adalah proses mengatur urutan data, mengorganisasikannya ke dalam suatu pola, kategori, dan uraian dasar. Definisi tersebut memberikan gambaran tentang betapa pentingnya kedudukan analisis dan dilihat dari segi tujuan penelitian. Prinsip pokok penelitian kualitatif adalah menemukan teori dari data.

Pada penelitian ini digunakan salah satu alat analisa yaitu metode SWOT (Strength, Weakness, Opportunity, Threats). SWOT adalah suatu bentuk analisis di dalam manajemen perusahaan atau dalam 
organisasi yang secara sistematis dapat membantu dalam usaha penyusunan suatu rencana yang matang untuk mencapai tujuan, baik tujuan jangka pendek maupun panjang. Analisis SWOT adalah penilaian terhadap hasil identifikasi situasi, untuk menentukan suatu kondisi dikategorikan sebagai kekuatan, kelemahan, peluang, dan ancaman. Dalam sumber lain disebutkan, analisis SWOT yaitu membandingkan kondisi lingkungan internal perusahaan dengan kondisi eksternal perusahaan.

Teknik analisis SWOT ini pada dasarnya merupakan satu teknik untuk mengenali berbagai kondisi yang berbasis bagi perencanaan strategi. Setelah mengenali isu permasalahan yang dihadapi secara toritis perlu dibangun kesepakatan antara steakholder mengenai apa yang diinginkan kedepan terhadap isu tersebut, komponen atau elemen apa yang diperlukan untuk lebih ditingkatkan, dikurangi atau justru diganti, memerlukan proses analisis yang banyak didasarkan pada peta kondisi SWOT dari isu tersebut.

\section{HASIL ANALISIS DAN PEMBAHASAN}

\subsection{Analisis Deskriptif}

Pada bagian ini akan dihadirkan beberapa data primer dari hasil wawancara langsung yang dilakukan kepada objek penelitian. Objek penelitian adalah pihak internal yaitu Bapak I Wayan Sudana selaku District Manager di PT. Mahakam Beta Farma cabang Lampung.

Berdasarkan hasil wawancara dengan District Manager PT. Mahakam Beta Farma cabang Lampung Bapak I Wayan Sudana, penerapan strategi pemasaran yang dilakukan oleh perusahaan yaitu dengan memilih merumuskan pasar yang dituju dengan menggunakan segmentasi (segmentation), targeting, dan positioning. Selain itu dengan mengembangkan marketing mix atau bauran pemasaran $4 \mathrm{P}$ yang terdiri dari produk, harga, promosi serta distribusi yang bertujuan untuk menarik pembeli dan mempertahankan pelanggan yang sudah ada.

Untuk lebih jelasnya mengenai strategi pemasaran Imforce Kaplet oleh PT. Mahakam Beta Farma, dapat diuraikan sebagai berikut :

\section{A) Segmentasi, Targeting, Positioning}

Segmentasi pasar ada beberapa variabel yang harus diperhatikan. Tujuannya agar segmentasi yang dilakukan tepat sasaran. Variabel untuk melakukan segmentasi pasar terdiri dari :

\section{Segmentasi berdasarkan geografis atau wilayah}

PT. Mahakam Beta Farma dalam menentukan segmentasi geografisnya lebih memfokuskan di kota-kota besar seperti Jakarta, Bandung, Lampung, Palembang, Yogyakarta, Bali, Medan dan lainnya. Karena di kota-kota besar banyak klinik dan rumah sakit yang ada dokter spesialis anak, dokter spesialis penyakit dalam, dan dokter spesialis kandungan yang menjadi target perusahaan ini.

\section{Segmentasi Demografis}

Segmentasi ini membagi pasar menjadi beberapa kelompok berdasarkan umur, jenis kelamin, pendapatan, pekerjaan, pendidikan, ras dan lain-lain. PT. Mahakam Beta Farma membidik semua variabel yang ada pada segmentasi ini karena produk Imforce Kaplet merupakan suplemen makanan yang bisa dikonsumsi dari segala usia, jenis kelamin dan lain sebagainya.

\section{Segmentasi berdasarkan Psikografis}

Segmentasi ini membagi kelompok pembeli yang berbeda-beda berdasarkan pada karakteristik kelas sosial, gaya hidup atau kepribadian. Dalam segmentasi ini PT. Mahakam Beta Farma membidik kelas sosial menengah keatas, yang memiliki gaya hidup tinggi untuk menjaga atau memelihara daya tahan tubuh. 
Setelah melakukan segmentasi, perusahaan tersebut melakukan targeting. Yang menjadi targeting pemasaran Imforce Kaplet adalah dokter umum, dokter spesialis penyakit dalam, dokter spesialis anak dan dokter spesialis kandungan. Untuk positioning PT. Mahakam Beta Farma dalam pemasaran Imforce Kaplet menyediakan produk yang berkualitas tinggi dengan harga bersaing dengan kompetitor dan aman digunakan oleh segala usia.

\section{B) Bauran Pemasaran (Marketing Mix)}

Setelah memutuskan seluruh segmentasi, targeting, dan positioning, PT. Mahakam Beta Farma selanjutnya merencanakan atau merumuskan bauran pemasaran/marketing mix yang memiliki 4 variabel sebagai berikut:

\section{Product (Produk)}

Produk adalah setiap apa saja yang ditawarkan ke pasar untuk mendapatkan perhatian pembeli, pemakai atau konsumen yang dapat memenuhi keinginan atau kebutuhan pemakainya. Strategi pemasaran Imforce Kaplet yang dilakukan PT. Mahakam Beta Farma adalah dengan menggunakan bahan-bahan berkualitas tinggi, terdaftar dalam BPOM (Badan Pengawas Obat dan Makanan), dan sudah teruji secara klinis kandungan yang ada di dalamnya. Untuk desain produk dibuat secara simpel tetapi menarik agar mudah diingat oleh pembeli.

\section{Price (Harga)}

Harga suatu barang dan jasa merupakan penentu bagi permintaan pasarnya. Harga dapat mempengaruhi posisi persaingan perusahaan dan juga mempengaruhi market share-nya. Bagi perusahaan, harga akan memberikan hasil dengan menciptakan sejumlah pendapatan dan keuntungan bersih. Harga suatu barang juga dapat mempengaruhi program perusahaan. PT. Mahakam Beta Farma dalam menetapkan harga Imforce Kaplet berdasarkan 2 faktor, yaitu biaya total + margin yang menjadikannya harga jual. Tetapi harga jual yang dikeluarkan perusahaan ini sesuai dengan kualitas barang yang diberikan dengan harga yang kompetitif dan harga yang pantas.

\section{Place (Tempat/Distribusi)}

Pelanggan Imforce Kaplet berada di hampir seluruh daerah di Indonesia. Agar barang sampai ke pembeli dengan cepat, strategi distribusi yang dilakukan oleh perusahaan adalah membuat stok disetiap cabang daerah. PT. Mahakam Beta Farma telah memiliki kantor pusat yang berada di Jakarta, lalu mempunyai kantor cabang di Lampung dan kota-kota besar lain. Jika ada pemesanan produk ke kantor pusat tetapi pembeli berada seandainya di daerah Tulang Bawang, maka pusat akan memproses orderan dan barang dikirim bukan dari kantor pusat, tetapi dari cabang terdekat dari lokasi pemesan berada yaitu di Bandar Lampung. Bila stok yang tersedia di cabang kurang, maka akan ada pengirimin dari pusat kembali kepada cabang dengan permintaan stok pada gudang di pusat. Untuk pengiriman ke setiap cabang, PT. Mahakam Beta Farma bekerja sama dengan salah satu perusahaan pengiriman kilat melalui darat, udara, dan laut yaitu SAP Express.

\section{Promotion (Promosi)}

Kegiatan promosi dalam PT. Mahakam Beta Farma adalah kegiatan yang sangat penting di dalam memasarkan produk Imforce Kaplet. Kegiatan inilah yang membuat konsumen tertarik pada produk yang kita punya. Dalam melaksanakan peningkatan volume penjualan, PT. Mahakam Beta Farma melakukan sistem promosi yang dilaksanakan oleh Medical Representative. Medical representative bisa didefinisikan sebagai duta perusahaan/seseorang yang dipercaya untuk mewakili perusahaan guna mempromosikan produknya secara profesional, kredibel, dan 
berintegritas kepada dokter, sehingga dokter tersebut yakin dan meresepkan produk perusahaannya kepada para pasien. Istilah lain medical representative adalah Medrep atau bisa juga detailer, karena dalam menjalankan tugasnya, seorang medical representative harus mampu menjelaskan seluk beluk produk yang ditawarkan secara detail kepada customernya.

\subsection{Anallisis SWOT}

Analisis SWOT atau TOWS adalah alat teknik penelitian kualitatif untuk mengidentifikasi berbagai faktor secara sistematis untuk merumuskan strategi dalam meningkatkan tingkat volume penjualan produk sebuah perusahaan. Analisis ini didasarkan pada logika yang dapat memaksimalkan kekuatan (strength) dan peluang (opportunities), namun secara bersamaan dapat meminimalisir kelemahan (weakness) dan ancaman (threats). Model yang dipakai pada tahap ini terdiri dari matriks faktor strategi internal dan matriks faktor strategi eksternal. Namun setelah membuat matriks IFAS faktor internal dan eksternal akan ditentukan terlebih dahulu dari bobot masing-masing (kekuatan, peluang, kelemahan, dan ancaman).

Tabel 4.1

Penentuan Bobot Faktor-faktor Kekuatan dan Kelemahan

\begin{tabular}{|c|c|c|l|l|}
\hline $\begin{array}{c}\text { Faktor- } \\
\text { faktor Segi } \\
\text { Internal }\end{array}$ & $\begin{array}{c}\text { Skal } \\
\text { a } \\
\text { Prior } \\
\text { itas } \\
\text { (SP) }\end{array}$ & $\begin{array}{c}\text { Konst } \\
\text { anta } \\
\text { (K) }\end{array}$ & $\begin{array}{l}\text { SP } \\
\mathbf{x}\end{array}$ & $\begin{array}{l}\text { Bo } \\
\text { bot }\end{array}$ \\
\hline \multicolumn{5}{|c|}{ Kekuatan } \\
\hline $\begin{array}{l}\text { Produk } \\
\text { yang } \\
\text { dijual } \\
\text { telah } \\
\text { teruji } \\
\text { secara }\end{array}$ & 4 & 4 & 16 & 0.1 \\
& & & & 3 \\
\hline
\end{tabular}

\begin{tabular}{|c|c|c|c|c|c|}
\hline & $\begin{array}{l}\text { klinis } \\
\text { dan } \\
\text { tidak } \\
\text { mengg } \\
\text { unakan } \\
\text { bahan- } \\
\text { bahan } \\
\text { berbaha } \\
\text { ya. }\end{array}$ & & & & \\
\hline 2 & $\begin{array}{l}\text { Harga } \\
\text { produk } \\
\text { yang } \\
\text { terjang } \\
\text { kau } \\
\text { oleh } \\
\text { konsum } \\
\text { en dan } \\
\text { bersain } \\
\text { g } \\
\text { dengan } \\
\text { perusah } \\
\text { aaan } \\
\text { sejenis. }\end{array}$ & 4 & 4 & 16 & $\begin{array}{c}0.1 \\
3\end{array}$ \\
\hline 3 & $\begin{array}{l}\text { Pengar } \\
\text { uh } \\
\text { lokasi } \\
\text { terhada } \\
\text { p } \\
\text { kelangs } \\
\text { ungan } \\
\text { usaha } \\
\text { yang } \\
\text { baik } \\
\text { dan } \\
\text { memili } \\
\text { ki } \\
\text { kantor } \\
\text { cabang } \\
\text { di } \\
\text { berbaga } \\
\text { i } \\
\text { daerah. }\end{array}$ & 3 & 4 & 12 & 0.1 \\
\hline 4 & $\begin{array}{l}\text { Kegiata } \\
\mathrm{n} \\
\text { promos } \\
\mathrm{i}\end{array}$ & 3 & 4 & 12 & 0.1 \\
\hline
\end{tabular}




\begin{tabular}{|c|c|c|c|c|c|}
\hline & $\begin{array}{l}\text { perusah } \\
\text { aan } \\
\text { mencak } \\
\text { upi } \\
\text { seluruh } \\
\text { aspek. }\end{array}$ & & & & \\
\hline 5 & $\begin{array}{l}\text { Memili } \\
\text { ki } \\
\text { jaringa } \\
\text { n yang } \\
\text { kuat } \\
\text { dan } \\
\text { berinte } \\
\text { gritas. }\end{array}$ & 3 & 4 & 12 & 0.1 \\
\hline 6 & $\begin{array}{l}\text { Memili } \\
\text { ki } \\
\text { sarana } \\
\text { fisik di } \\
\text { kantor } \\
\text { pusat } \\
\text { dan } \\
\text { cabang, } \\
\text { serta } \\
\text { fasilitas } \\
\text { dan } \\
\text { peralata } \\
\text { n } \\
\text { kantor } \\
\text { yang } \\
\text { baik } \\
\text { untuk } \\
\text { menunj } \\
\text { ang } \\
\text { produkt } \\
\text { ifitas } \\
\text { karyaw } \\
\text { an. }\end{array}$ & 3 & 4 & 12 & 0.1 \\
\hline 7 & $\begin{array}{l}\text { Reputa } \\
\text { si dan } \\
\text { citra } \\
\text { positif } \\
\text { dari } \\
\text { masyar } \\
\text { akat } \\
\text { terhada } \\
\text { p }\end{array}$ & 3 & 4 & 12 & 0.1 \\
\hline
\end{tabular}

\begin{tabular}{|c|c|c|c|c|c|}
\hline & $\begin{array}{l}\text { perusah } \\
\text { aan. }\end{array}$ & & & & \\
\hline \multicolumn{6}{|c|}{ Kelemahan } \\
\hline 1 & $\begin{array}{l}\text { Masih } \\
\text { adanya } \\
\text { SDM } \\
\text { yang } \\
\text { kurang } \\
\text { kompet } \\
\text { en. }\end{array}$ & 3 & 4 & 12 & 0.1 \\
\hline 2 & $\begin{array}{l}\text { Sumber } \\
\text { keuang } \\
\text { an } \\
\text { terbatas }\end{array}$ & 2 & 4 & 8 & $\begin{array}{c}0.0 \\
7\end{array}$ \\
\hline 3 & $\begin{array}{l}\text { Ketidak } \\
- \\
\text { singkro } \\
\text { nan } \\
\text { antara } \\
\text { karyaw } \\
\text { an } \\
\text { dengan } \\
\text { atasan } \\
\text { yang } \\
\text { kurang } \\
\text { dalam } \\
\text { menjala } \\
\text { nkan } \\
\text { tujuan } \\
\text { perusah } \\
\text { aan . }\end{array}$ & 2 & 4 & 8 & $\begin{array}{c}0.0 \\
7\end{array}$ \\
\hline \multicolumn{4}{|c|}{ Total SP x K } & $\begin{array}{l}12 \\
0\end{array}$ & 1.0 \\
\hline
\end{tabular}

Berdasarkan tabel 4.1 penentuan bobot faktor-faktor kekuatan dan kelemahan diatas maka dapat dibuat faktor-faktor strategi yang hasilnya ditunjukan kepada tabel IFAS disusun untuk merumuskan faktor-fakor strategi internal tersebut dalam kerangka kekuatan (strenght) dan kelemahan (weakness) perusahaan. 
Tabel 4.2 IFAS (Internal Factor Analisis Summary)

\begin{tabular}{|c|c|c|c|}
\hline $\begin{array}{c}\text { Faktor-faktor } \\
\text { Internal }\end{array}$ & $\begin{array}{c}\text { Bob } \\
\text { ot }\end{array}$ & $\begin{array}{c}\text { Ra } \\
\text { tin } \\
\mathbf{g}\end{array}$ & Skor \\
\hline 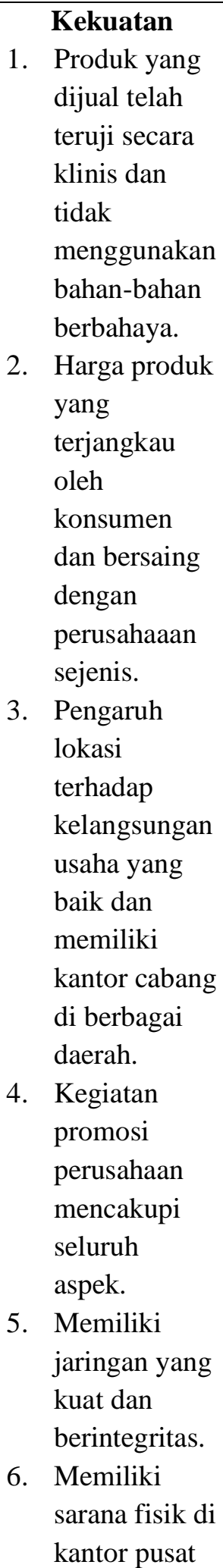 & $\begin{array}{c}0.13 \\
0.13 \\
0.1\end{array}$ & $\begin{array}{l}3 \\
3\end{array}$ & $\begin{array}{c}0.52 \\
0.52 \\
0.3\end{array}$ \\
\hline
\end{tabular}

\begin{tabular}{|c|c|c|c|c|}
\hline 7. & $\begin{array}{l}\text { dan cabang, } \\
\text { serta fasilitas } \\
\text { dan peralatan } \\
\text { kantor yang } \\
\text { baik untuk } \\
\text { menunjang } \\
\text { produktifitas } \\
\text { karyawan. } \\
\text { Reputasi dan } \\
\text { citra positif } \\
\text { dari } \\
\text { masyarakat } \\
\text { terhadap } \\
\text { perusahaan. }\end{array}$ & & & \\
\hline & Sub Total & 0.76 & & 2.54 \\
\hline \multicolumn{2}{|r|}{ Kelemahan } & \multirow{16}{*}{$\begin{array}{c}0.1 \\
0.07 \\
0.07\end{array}$} & \multirow{16}{*}{$\begin{array}{l}3 \\
2 \\
2\end{array}$} & \multirow{16}{*}{$\begin{array}{c}0.3 \\
0.14 \\
0.14\end{array}$} \\
\hline 1 & Masih adanya & & & \\
\hline & SDM yang & & & \\
\hline & kurang & & & \\
\hline & kompeten. & & & \\
\hline 2 & Sumber & & & \\
\hline & keuangan & & & \\
\hline \multirow{11}{*}{3} & Ketidak- & & & \\
\hline & singkronan & & & \\
\hline & antara & & & \\
\hline & karyawan & & & \\
\hline & dengan atasan & & & \\
\hline & yang kurang & & & \\
\hline & dalam & & & \\
\hline & menjalankan & & & \\
\hline & $\begin{array}{l}\text { tujuan } \\
\text { perusahaan }\end{array}$ & & & \\
\hline & Sub Total & 0.24 & & 0.58 \\
\hline & Total & 1.0 & & 3.12 \\
\hline
\end{tabular}

Tabel 4.3 Penentuan Bobot Faktorfaktor Peluang dan Ancaman

\begin{tabular}{|c|c|c|c|c|}
\hline $\begin{array}{c}\text { Faktor- } \\
\text { faktor Segi } \\
\text { Eksternal }\end{array}$ & $\begin{array}{c}\text { Skala } \\
\text { Priori } \\
\text { tas } \\
\text { (SP) }\end{array}$ & $\begin{array}{c}\text { Kons } \\
\text { tanta } \\
\text { (K) }\end{array}$ & $\begin{array}{c}\text { SP } \\
\text { x K }\end{array}$ & $\begin{array}{c}\text { Bob } \\
\text { ot }\end{array}$ \\
\hline \multicolumn{6}{|c|}{ Peluang } \\
\hline $\begin{array}{c}\text { Citra } \\
\text { positif }\end{array}$ & 4 & 4 & 16 & 0.2 \\
\hline
\end{tabular}




\begin{tabular}{|c|c|c|c|c|c|}
\hline & $\begin{array}{l}\text { masyarak } \\
\text { at yang } \\
\text { menimbu } \\
\text { lkan } \\
\text { kepercay } \\
\text { aan } \\
\text { terhadap } \\
\text { produk } \\
\text { Imforce } \\
\text { Kaplet. }\end{array}$ & & & & \\
\hline 2 & $\begin{array}{l}\text { Kesadara } \\
\mathrm{n} \\
\text { masyarak } \\
\text { at akan } \\
\text { pentingny } \\
\text { a } \\
\text { menjaga } \\
\text { dan } \\
\text { memeliha } \\
\text { ra daya } \\
\text { tahan } \\
\text { tubuh. }\end{array}$ & 3 & 4 & 12 & 0.15 \\
\hline 3 & $\begin{array}{l}\text { Imforce } \\
\text { Kaplet } \\
\text { dapat } \\
\text { digunaka } \\
\text { n oleh } \\
\text { segala } \\
\text { jenis usia. }\end{array}$ & 3 & 4 & 12 & 0.15 \\
\hline 4 & $\begin{array}{l}\text { Pemberia } \\
\mathrm{n} \\
\text { sponsorsh } \\
\text { ip } \\
\text { terhadap } \\
\text { tenaga } \\
\text { kesehatan } \\
\text { mempeng } \\
\text { aruhi } \\
\text { peningkat } \\
\text { an } \\
\text { penjualan } \\
\text {. }\end{array}$ & 4 & 4 & 16 & 0.2 \\
\hline \multicolumn{6}{|c|}{ Ancaman } \\
\hline 1 & $\begin{array}{l}\text { Persainga } \\
\mathrm{n} \text { tinggi }\end{array}$ & 2 & 4 & 8 & 0.1 \\
\hline
\end{tabular}

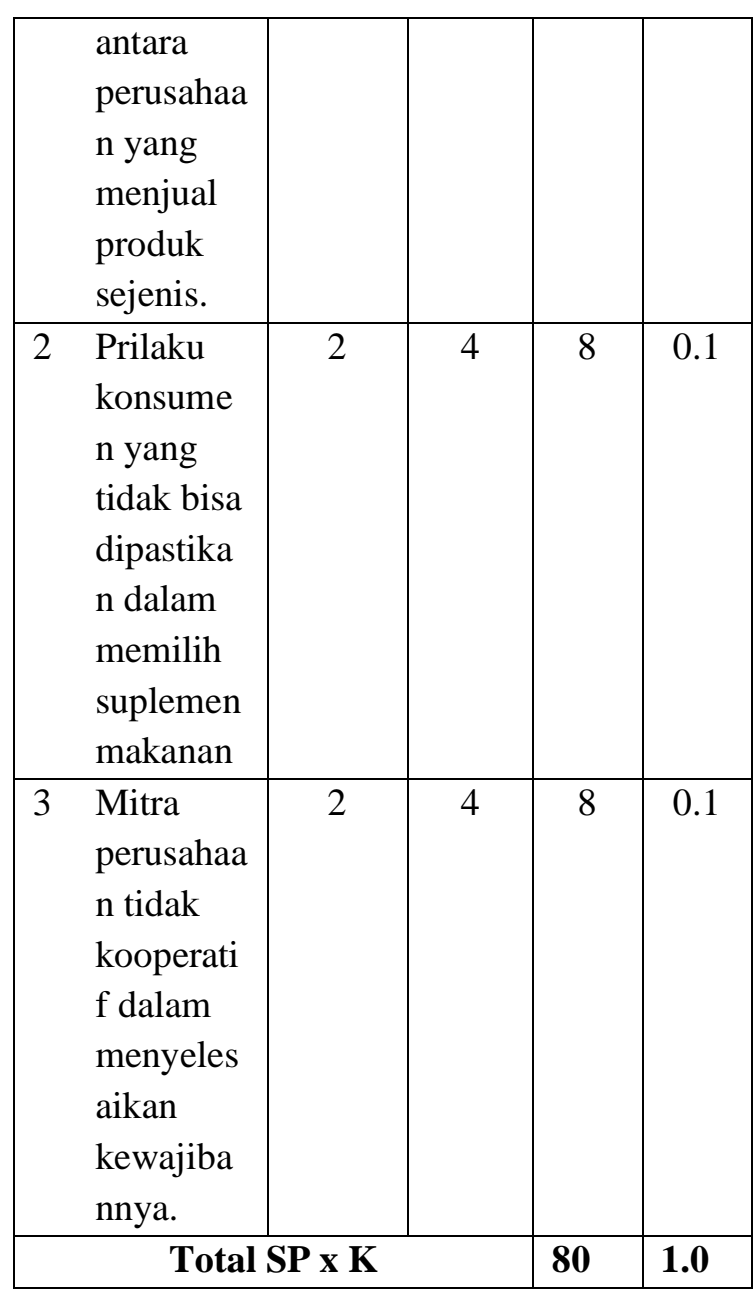

Berdasarkan tabel 4.3 penentuan bobot faktor-faktor peluang dan ancaman diatas maka dapat dibuat faktor-faktor strategi yang hasilnya ditunjukan pada tabel EFAS disusun untuk merumuskan faktor-faktor strategi ekternal tersebut dalam kerangka peluang (opportunities) dan ancaman (threats) perusahaan.

Berdasarkan hasil perhitungan, faktor internal kekuatan yang dimiliki PT. Mahakam Beta Farma lebih besar dari faktor kelemahannya, yaitu sebesar 1.96, yang mana angka 1.96 merupakan selisih dari total kekuatan sebesar 2.54 dengan total kelemahan sebesar 0.58, dan untuk faktor eksternal peluang yang dimiliki perusahaan tersebut lebih besar dari faktor ancamannya yaitu sebesar 1.9 yang dimana merupakan selisih dari total peluang sebesar 2.5 dengan total ancaman sebesar 
0.6. Dari perhitungan tersebut dapat diperoleh formulasi strategi pemasaran yang sesuai.

Berdasarkan diagram cartesius diatas, sangat jelas menunjukan bahwa PT. Mahakam Beta Farma telah berada pada jalur yang tepat yaitu di kuadran I yang menunjukan bahwa perusahaan ini masih tergolong perusahaan yang berkembang. Meskipun masih dalam perusahaan berkembang, PT. MBF harus memperhatikan peluang dan ancaman baik dari internal maupun eksternal. Dengan memperhatikan faktor-faktor yang sudah dijelaskan tentu akan meningkatkan pertumbuhan volume penjualan pada produk Imforce Kaplet.

\subsection{Matriks SWOT}

Matriks SWOT merupakan matriks yang disusun menggunakan variabel- variabel kekuatan, kelemahan, peluang, serta ancaman yang diidentifikasi dalam faktorfaktor strategi internal dan faktor eksternal. Matriks SWOT ini menggambarkan bagaimana peluang dan ancaman dari lingkungan eksternal perusahaan dapat disesuaikan dengan kekuatan dan kelemahan yang dimiliki perusahaan. Analisis dengan menggunakan matriks SWOT ini menggunakan data yang diperoleh dari tabel faktor strategi internal dan faktor strategi internal PT. Mahakam Beta Farma.

Berdasarkan analisis tersebut menujukkan bahwa kinerja perusahaan dapat ditentukan oleh kombinasi faktor internal dan eksternal. Kombinasi kedua faktor tersebut ditunjukkan dalam diagram hasil analisis SWOT sebagai berikut:

\section{Strategi SO Strength Opportunities (mendukung sebagai growth)}

Strategi ini dibuat berdasarkan jalan pikiran perusahaan, yaitu dengan memanfaatkan seluruh kekuatan untuk merebut dan memanfaatkan peluang sebesar-besarnya. Strategi SO yang di tempuh oleh PT. Mahakam Beta Farma yaitu:

a. Mempertahankan dan meningkatkan kualitas produk Imforce Kaplet agar masyarakat terus percaya pada produk tersebut. Dengan mempertahankan kualitas diharapkan konsumen menjadi lebih puas dengan produk tersebut dan akan terus dipakai atau dibeli oleh konsumen. Strategi ini digunakan agar masyarakat menjadi lebih percaya terhadap produk Imforce Kaplet dengan cara mempertahankan mutu dan kualitas.

b. Memperdalam jalinan terhadap mitra guna menciptakan hubungan yang baik. Strategi ini diperlukan karena hubungan yang baik dapat mendatangkan hasil yang positif bagi mitra dan PT. Mahakam Beta Farma.

c. PT. Mahakam Beta Farma membuat promosi yang menarik untuk meningkatkan kesadaran masyarakat Indonesia akan pentingnya menjaga dan memelihara daya tahan tubuh. Promosi yang menarik dari perusahaan dapat mengedukasi kesadaran masyarakat. Kesadaran masyarakat akan pentingnya menjaga dan memelihra daya tahan tubuh diharapkan dapat meningkatkan volume penjualan suplemen makanan Imforce Kaplet.

\section{Strategi WO Weakness}

Opportunities (mendukung strategi Turn Around)

Strategi ini untuk mengatasi kelemahan dengan memanfaatkan peluang yang ada. Strategi yang mungkin dapat dilakukan yaitu PT. Mahakam Beta Farma mengadakan penyamaan visi misi kepada karyawan perusahaan melalui pelatihan sehingga tercapainya tujuan perusahaan guna meningkatkan kepercayaan masyarakat. Pelatihan yang tepat dan efektif kepada karyawan dapat memberikan 
dampak langsung terhadap pencapaian tujuan perusahaan. Tujuan perusahaan yang tercapai dengan baik diharapkan dapat meningkatkan kepercayaan masyarakat dalam menggunakan produk Imforce Kaplet.

\section{Strategi ST Strength Threats (mendukung strategi diversifikasi)}

Strategi ini menggunakan kekuatan yang dimiliki perusahaan untuk mengatasi ancaman. Strategi ST yang ditempuh PT. Mahakam Beta Farma yaitu :

a. Terus melakukan inovasi dan meningkatkan kualitas produk guna mengungguli persaingan perusahaan sejenis. Agar dapat unggul dan mendominasi dengan kompetitor perusahaan, inovasi dan peningkatan kualitas produk dianggap penting untuk diterapkan.

b. Meningkatkan dan memperluas jaringan pemasaran agar dapat mempengaruhi konsumen dalam pengambilan keputusan produk suplemen makanan. Jaringan pemasaran yang luas dan terstruktur diharapkan dapat mempengaruhi konsumen dalam pengambilan keputusan. Pengambilan keputusan konsumen untuk mengonsumsi suplemen makanan yang ditawarkan PT. Mahakam Beta Farma diharapkan dapat meningkatkan volume penjualan perusahaan.

c. Kantor cabang di berbagai daerah dapat meningkatkan fungsi pengawasan untuk menghindari atau mengurangi mitra yang tidak kooperatif. Peningkatan fungsi pengawasan dari kantor cabang PT. Mahakam Beta Farma diharapkan dapat menciptakan hubungan yang baik dengan mitra perusahaan. Peningkatan fungsi pengawasan dapat membuat hubungan tersebut menjadi lebih efektif dan terstruktur.

\section{Strategi WT Weakness Threats (mendukung strategi difensif)}

Strategi ini didasarkan pada kegiatan yang bersifat defensive dan berusaha meminimalkan kelemahan yang ada serta menghindari ancaman. Strategi WT yang di tempuh oleh PT. Mahakam Beta Farma yaitu :

a. PT. Mahakam Beta Farma terus meningkatkan kualitas hubungan internal dan eksternal perusahaan agar dapat mengungguli persaingan dengan perusahaan sejenis. Kualitas hubungan internal dan eksternal yang terjaga integritasnya membuat PT. Mahakam Beta Farma dapat menguasai persaingan dan unggul pada pasar sehingga diharapkan dapat meningkatkan volume penjualan.

Dari empat kemungkinan alternatif strategi yang diperoleh diatas, strategi yang paling tepat digunakan oleh PT. Mahakam Beta Farma dalam meningkatkan volume penjualan suplemen makanan Imforce Kaplet adalah strategi SO yaitu strategi dengan menggunakan strength untuk memanfaatkan opportunities yang dimiliki perusahaan yaitu :

a Mempertahankan dan meningkatkan kualitas produk agar masyarakat lebih percaya. Strategi ini digunakan agar masyarakat menjadi lebih percaya terhadap suplemen makanan Imforce Kaplet yang dipasarkan PT. Mahakam Beta Farma dengan cara terus meningkatkan mutu dan kualitas produk.

b Memperdalam jalinan dengan mitra guna menciptakan hubungan yang baik. Strategi ini diperlukan karena hubungan yang baik dapat mendatangkan hasil positif bagi mitra maupun perusahaan.

c PT. Mahakam Beta Farma membuat promosi yang menarik untuk meningkatkan kesadaran masyarakat 
akan pentingnya menjaga dan memelihara daya tahan tubuh. Promosi yang menarik dari perusahaan dapat mengedukasi kesadaran masyarakat. Kesadaran masyarakat akan pentingnya menjaga dan memelihara daya tahan tubuh diharapkan dapat meningkatkan volume penjualan suplemen makanan Imforce Kaplet.

Berdasarkan hasil analisis SWOT PT. Mahakam Beta Farma memiliki kekuatan yang dapat dipakai pada strategi tertentu serta memanfaatkan peluang yang tepat serta secara bersamaan sehingga dapat meminimalisir atau menghindari kelemahan dan ancaman yang ada. Posisi ini sangat menguntungkan perusahaan dengan memperbaiki kondisi diatas rata-rata kemampuan sehingga PT. Mahakam Beta Farma dapat mengendalikan para pesaing yang ada maupun pesaing yang terbilang kuat.

\section{KESIMPULAN DAN SARAN}

\subsection{Kesimpulan}

Berdarsarkan hasil analisis dan pembahasan, maka dapat disimpulkan beberapa hal sebagai berikut:

1. Dalam melakukan strategi pemasaran suplemen makanan Imforce Kaplet, PT. Mahakam Beta Farma menerapkan segmentasi, targetting, dan positioning dengan benar dan tepat. Lalu perusahaan tersebut menggunakan Bauran Pemasaran (Marketing Mix) $4 \mathrm{P}$ yang terdiri dari strategi produk (Product), strategi harga (Price), strategi promosi (Promotion), dan strategi penentuan lokasi (Place).

2. Berdasarkan analisis internal dan eksternal perusahaan beserta diagram Cartesius dapat diperoleh bahwa yang menjadi strategi utama dari PT. Mahakam Beta Farma dalam memasarkan produk suplemen makanan Imforce Kaplet adalah strategi Growth. Yang man PT. Mahakam
Beta Farma dapat mempertahankan dan meningkatkan kualitas produk agar masyarakat terus percaya produk suplemen makanan Imforce Kaplet. Lalu memperdalam jalinan dengan mitra guna menciptakan hubungan yang baik serta membuat promosi yang menarik untuk meningkatkan kesadaran masyarakat akan pentingnya menjaga dan memelihara daya tahan tubuh. Berdasarkan matriks SWOT maka dapat disimpulkan beberapa pengembangan melalui pertimbangan faktor internal dan eksternal peusahaan yang dapat bermanfaat bagi kemajuan PT. Mahakam Beta Farma.

\subsection{Saran}

Berdasarkan pengamatan penulis mengenai strategi pemasaran produk suplemen makanan Imforce Kaplet yang diterapkan oleh PT. Mahakam Beta Farma, maka adapun saran yang ingin penulis sampaikan sebagai alternatif perusahan adalah sebagai berikut :

1. PT. Mahakam Beta Farma seharusnya mengadakan sistem promosi pengiklanan produk Imforce Kaplet melalui Digital Media seperti televisi ataupun media online serta melalui media cetak seperti koran ataupun majalah agar masyarakat luas juga bisa mengetahui produk tersebut. Karena Imforce Kaplet merupakan suplemen makanan/Vitamin yang bisa di konsumsi semua masyarakat tanpa harus menggunakan resep dari dokter atau bisa dikatakan bukan obat keras yang bisa fatal jika dikonsumsi tidak seusai anjuran dosis atau saran dari Dokter.

2. Untuk meningkatkan pengembangan, PT. Mahakam Beta Farma harus meningkatkan kualitas produk guna menarik kepercayaan agar terus digunakan oleh konsumen dan membuat diferensiasi produk. Dengan pengembangan produk baru akan menimbulkan ketertarikan konsumen pada inovasi produk tersebut. 
Terus meningkatkan kegiatan promosi semenarik mungkin dari promosi harga maupun lainnya guna membuat konsumen tertarik pada produk perusahaan yang akan meningkatkan volume penjualan.

\section{DAFTAR PUSTAKA}

American Marketing Association (AMA) yang dikutip oleh Philip Kotler dan Keller Kevin Lane yang diterjemahkan oleh Bob Sabran. 2009

[BPOM] Badan Pengawas Obat dan Makanan Republik Indonesia. 2004. Peraturan Kepala Badan Pengawas Obat dan Makanan Republik Indonesia nomor HK.005.05.23.3644.BPOM. Jakarta

Philip \& Duncan. (2012). Marketing Principles and Methods. Georgetown: Richard D. Irwin. Inc

Greger, J.I. 2001. Dietary Suplement Use : Consumer Characteristics and Interest. Journal of Nutrition, 131 ; 1339513435.

Jauch Lawrence R. \& Glueck William F. (1989). Manajemen Dan Strategis Kebijakan Perusahaan. Jakarta: Erlangga

Kotler, Philip. 2000. Manajemen Pemasaran di Indonesia. Salemba Empat. Jakarta

Kotler, Philip and Garry Armstrong. 2008. Prinsip-prinsip Pemasaran. Jilid I. Erlangga. Jakarta

Lyle, B.J,et. Al. 1998. Supplement Users Differ from Nonusers in Demographic, Life Style, Dietary and Health Characterisctics. The Journal of Nutrition vol. 128 no. 12, pp. 23552362
Stanton, William J.2003. Prinsip Pemasaran (terjemahan). Edisi 7,jilid 1.Erlangga. Jakarta.

Waringin, Tung Dasem. (2008). Marketing Revolution. PT. Gramedia Pustaka Utama, Jakarta.

Westwood, John. 2006. How to write marketing plan. Jakarta: PT Elex Media Komputindo

Zoelandari, Mita (2007). Perkembangan Mata VS Kecerdasan Anak.

\section{Sumber Lain}

Arif, Efendi, (2019). Modul Medical Representatif. [Internet]. Tersedia di: https://id.scribd.com/doc/214181843/M odul-Medical-Representative...

Halodoc, (2019). Imforce Plus 6 Kaplet.[Internet]. Tersedia di: http://www.halodoc.com/obat-danvitamin/imforce-plus-6-kaplet.

Maxmanroe, (2019). Pengertian Pemasaran. [Internet]. Tersedia di: http://www.maxmanroe.com/vid/marke ting/pengertian-pemasaran.html\#.

Paimin, (2014). Profil PT Mahakam Beta Farma.[Internet]. Tersedia di: https://paimin92-wordpresscom.cdn.ampproject.org. 